\title{
More resistant tendons obtained from the association of Heteropterys aphrodisiaca and endurance training
}

\author{
Juliana C Monteiro ${ }^{1}$, Marcos LM Gomes ${ }^{2}$, Tatiana C Tomiosso ${ }^{3}$, Wilson R Nakagaki ${ }^{2}$, Mariana M Sbervelheri², \\ Danilo L Ferrucci ${ }^{4}$, Edson R Pimentel ${ }^{2}$ and Heidi Dolder ${ }^{2^{*}}$
}

\begin{abstract}
Background: Popular Brazilian medicine uses Heteropterys aphrodisiaca infusion as a tonic or stimulant, for the treatment of nervous debility and breakdown and for muscle and bone weakness. This study investigated the effects of Heteropterys aphrodisiaca infusion on the tendon properties and extracellular matrix of rats under endurance training.
\end{abstract}

Methods: Wistar rats were grouped as follows: CS- control sedentary, HS- H. aphrodisiaca sedentary, CT-control trained, HT- H. aphrodisiaca trained. The training protocol consisted in running on a motorized treadmill, five times a week, with weekly increase in treadmill speed and duration. Control groups received water while the HS and HT groups received $H$. aphrodisiaca infusion, daily, by gavage for the 8 weeks of training. Achilles tendons were frozen for biochemical and biomechanical analysis or preserved in Karnovsky's fixative, then processed for histomorphological analysis with light microscopy.

Results: Biomechanical analysis showed significant increase in maximum load, maximum stress, modulus of elasticity and stiffness of the HT animals' tendons. The metalloproteinase-2 activity was reduced in the HT group. The compression region of HT animals' tendons had a stronger and more intense metachromasy, which suggests an increase in glycosaminoglycan concentration in this region of the tendon. The most intense birefringence was observed in both compression and tension regions of HT animals' tendons, which may indicate a higher organizational level of collagen bundles. The hydroxyproline content increased in the HT group.

Conclusions: The association of endurance training with $\mathrm{H}$. aphrodisiaca resulted in more organized collagen bundles and more resistant tendons to support higher loads from intense muscle contraction. Despite the clear anabolic effects of Heteropterys aphrodisiaca and the endurance exercise association, no side effects were observed, such as those found for synthetic anabolic androgenic steroids.

\section{Background}

Heteropterys aphrodisiaca O. Mach. (Malpighiaceae), also known as "nó-de-cachorro", "nó-de-porco" and "cordão-de-São-Francisco", was described by Hoehne in 1920 as a plant with stimulative and aphrodisiac properties. Also, Brazilian traditional medicine uses H. aphrodisiaca root infusion as a tonic or stimulating treatment and for nervous debility, nervous breakdown and for

\footnotetext{
* Correspondence: heidi@unicamp.br

2Departamento de Biologia Estrutural e Funcional, Instituto de Biologia, Universidade Estadual de Campinas, CEP 13083-863, CP 6109, Campinas, SP, Brasil

Full list of author information is available at the end of the article
}

muscle and bone weakness. This plant is found mainly in the "Cerrado" regions (a savanna-like biome) of Mato Grosso and Goiás States (Brazil) [1,2].

Previous studies with $H$. aphrodisiaca suggested that the root extract could increase corporal and testicular weight, as well as Leydig cell volume within the rat testis $[3,4]$. Leydig cells produce testosterone, thus regulating muscle protein metabolism, erythropoiesis, plasma lipids, bone metabolism and cognitive functions [5]. Since testosterone regulates growth, structure and functions of accessory sex organs [6] and the treatment with $H$. aphrodisiaca infusion showed no alterations of these
C Biomed Central

(c) 2011 Monteiro et al; licensee BioMed Central Ltd. This is an Open Access article distributed under the terms of the Creative Commons Attribution License (http://creativecommons.org/licenses/by/2.0), which permits unrestricted use, distribution, and reproduction in any medium, provided the original work is properly cited. 
organs' weights, Chieregato [3] suggested this hormone resulted in weight gain since it acts on the skeletal muscle mass.

Higher doses of anabolic androgenic steroids (AAS), when combined with a training program, have been claimed to increase muscle strength and mass [7]. However, some reports have mentioned that tendons do not follow the same rate of protein gain as achieved by the muscle bulk, and therefore high intensity and frequency of training might lead to tendon ruptures $[8,9]$. Some studies using animals suggested that steroids modify the collagen crimp pattern and tendon biomechanical properties [10]. Steroid use may cause collagen dysplasia in the flexor digitorum tendon of mice [11], increasing tendon stiffness and diminishing both elongation and energy absorption [12,13]. Thus, such tendons are more likely to fail during strenuous activities. In addition, AAS treatment can impair tendon tissue remodeling by down regulating matrix metalloproteinase (MMP) activity in animals undergoing physical exercise, hence increasing the potential for tendon injury [14]. In human beings, morphological changes at the muscle-tendon junction, as well as tendon ruptures were found when anabolic steroids were associated with exercise [15]. High intensity loads during exercise seem to play a role in the process that allows the deleterious effects of steroids to be manifested. In the above studies, the groups that had been treated with both steroids and exercise suffered the worst injuries.

The response of tendons to exercise and some treatments may be analyzed regarding structural, chemical and mechanical aspects. However, most studies have been limited to analysis of only one or two of these aspects [16]. The present study aggregates biochemical, structural and biomechanical data in order to precisely investigate the effects of $H$. aphrodisiaca infusion on the tendon properties under long term endurance training. This study is part of a comprehensive study dealing with the effects of $H$. aphrodisiaca administration and intensive endurance exercise on some biological systems.

\section{Methods}

\section{Animals}

Adult Wistar rats, 90 days old, were obtained from the Center for Biological Investigation - CEMIB (State University of Campinas, Campinas, SP, Brazil). The rats were housed, three per cage, under standard conditions with $12 \mathrm{~h} \mathrm{~L}: 12 \mathrm{~h}$ D cycle. Animals were provided with commercial rat feed and water ad libitum. The Institutional Committee for Ethics in Animal Care and Use of this University approved the experimental protocol (process $\left.n^{\circ} 1233-1\right)$.

\section{Medicinal Plant}

H. aphrodisiaca roots were collected in February 2007, in Mato Grosso State, Brazil. The species was identified by comparison with the voucher herbarium specimen of the plant at the Herbarium of the Mato Grosso Federal University, Brazil (number 23928). The roots were dried at room temperature, crushed and powdered using a grinding mill. The infusion was routinely prepared by pouring $100 \mathrm{~mL}$ of boiling water over 25 g of powdered roots, which was allowed to steep for 4 hours, then filtered by using filter paper. The yield was an infusion of $68.66 \mathrm{mg}$ of dry extract $(6.866 \% \mathrm{w} / \mathrm{v})$ and a yield of $6.832 \%(\mathrm{w} / \mathrm{w})$ in terms of initial crude dry weight of plant material. The infusion was prepared every four days and stored in the refrigerator. The doses of $H$. aphrodisiaca were selected according to previous studies [4].

\section{Study groups and experimental protocol}

Forty-eight male rats were divided into four groups ( $\mathrm{n}=$ 12/group): two sedentary (CS and HS) and two submitted to involuntary running on a motorized treadmill (CT and HT). All groups received either $0.5 \mathrm{~mL}$ of distilled water (CS and CT, control groups) or $H$. aphrodisiaca infusion (HS and HT). Either water or infusion (104 $\mathrm{mg} /$ day) was administered by gavage during the 8 weeks of both training and sedentary periods. Trained rats (group CT and HT) were allowed to adapt to treadmill running for a 3 week period, prior to the beginning of the experimental protocol, which consisted of low to moderate level exercise carried out daily for 5 days a week (Table 1). After adaptation, trained rats were subjected to 8 weeks of intensive aerobic exercise training (treadmill running), also on a weekly cycle of 5 consecutive exercising days followed by a two day rest, as shown in Table 1, adapted from [17-20]. This program is a form of endurance training and does not compare with power training [18]. Forty-eight hours after the last training, the rats were anesthetized with xylazine chloride (Anasedan, Vetbrands, São Paulo, Brazil) and ketamine chloride (Cetamin, Syntec, Cotia, Brazil) (5 and 80 $\mathrm{mg} / \mathrm{Kg}$ body weight, respectively). The right and left tendons were excised and frozen for biochemical,

\section{Table 1 Exercise protocol in treadmill running}

\begin{tabular}{cccc}
\hline Event & Week & Velocity $(\mathrm{m} / \mathrm{min})$ & Duration $(\mathrm{min})$ \\
\hline Treadmill & 1 & 10.68 & 5 \\
adaptation & 2 & 12.42 & 7,5 \\
& 3 & 14.16 & 10 \\
\hline \multirow{2}{*}{ Training } & 1 & 14.16 & 20 \\
& 2 & 19.62 & 30 \\
& 3 & 19.62 & 40 \\
& $4-8$ & 22.92 & 45 \\
\hline
\end{tabular}


biomechanical and zymographical analysis or preserved in Karnovsky's fixative for morphological analysis.

\section{Light Microscopy Analysis}

Tendon samples ( $n=4$ /group) were immersed in Karnovsky's fixative for $24 \mathrm{~h}$ and then processed for paraffin embedding (Histosec, Merck). Longitudinal serial sections, $7 \mu \mathrm{m}$ thick, were stained with toluidine blue $(0.025 \%)$ in Mcllvaine buffer $(0.03 \mathrm{M}$ citric acid, $0.04 \mathrm{M}$ sodium phosphate, dibasic - $\mathrm{pH} 4.0$ ) and observed by polarized and conventional light microscopy. The organization of collagen bundles was examined with a Nikon E800 microscope (polarized light microscopy), connected with Cool Snap Pro-Color camera (Media Cibernetica). Polarized light microscopy of a highly ordered fiber, such as collagen, shines brightly. To assess birefringence, the analyzer and the polarizer were crossed and the material was positioned at an angle of $45^{\circ}$ relative to the polarizer. Proteoglycans were detected in extracellular matrix tissue sections stained with Toluidine Blue ( $\mathrm{pH} 4.0)$ and observed under an Olympus BX 41 light microscope (conventional light microscopy). Since proteoglycans have many closely placed negative radicals, sections with high concentrations of proteoglycans, stained with toluidine blue, determine closely arranged and interacting molecules of this stain, replacing the blue with a violet coloring.

\section{Extraction procedures}

The tendons ( $n=4 /$ group) were treated with 25 volumes of $4 \mathrm{M}$ guanidine chloride $(\mathrm{GuHCl})$, containing $1 \mathrm{mM}$ phenylmethylsulfonyl fluoride (PMSF) and 20 $\mathrm{mM}$ ethylenediamine tetraacetic acid (EDTA) in $50 \mathrm{mM}$ sodium acetate buffer, pH 5.8 (Heinegård and Sommarin, 1987) at $4^{\circ} \mathrm{C}$ for $24 \mathrm{~h}$. The mixture was then centrifuged $\left(20,000 \times \mathrm{g}, 4^{\circ} \mathrm{C}, 30 \mathrm{~min}\right)$, the supernatant precipitated in acetate-ethanol and used in the biochemical analyses.

\section{Electrophoresis (SDS-PAGE)}

SDS-PAGE was performed according to Zingales [21], using gradient gels (4-16\%). The tendon extracts $(50 \mu \mathrm{L})$ from all experimental groups were precipitated with 100 $\mu \mathrm{L}$ of $50 \mathrm{mM}$ acetate buffer, $\mathrm{pH} 7.4$, and 9 volumes of absolute ethanol, for $24 \mathrm{hr}$ at $4{ }^{\circ} \mathrm{C}$. These samples were analyzed by SDS-PAGE $(50 \mu \mathrm{L})$. Gels were stained with Coomassie Brilliant Blue R-250. The relative molecular masses were estimated by comparisons with protein standard molecular mass markers.

\section{Quantitative analysis}

The amount of proteins in the extract of $\mathrm{GuHCl}$ was measured by the Bradford method [22], using bovine serum albumin (BSA) $(1 \mathrm{mg} / \mathrm{mL})$ as a standard. The readings were performed in a micro-plate reader at 595 $\mathrm{nm}$. Sulfated glycosaminoglycans (GAG) of $\mathrm{GuHCl}$ extracts were quantified by the dimethylmethylene blue method (DMMB) [23] using chondroitin sulphate (1 $\mathrm{mg} / \mathrm{mL}$ ) as a standard, and readings were performed in a micro-plate reader at $526 \mathrm{~nm}$. To quantify hydroxyproline, tendon fragments $(n=4)$ were dehydrated in acetone for $48 \mathrm{~h}$ and, subsequently, for another 24 hours in a mixture of chloroform and ethanol, at a ratio of $2: 1$. The tendon fragments were then hydrolyzed in 6 $\mathrm{N} \mathrm{HCl}(10 \mathrm{mg}$ of tissue $/ \mathrm{mL})$, for $18 \mathrm{~h}$ at $120^{\circ} \mathrm{C}$, and the hydrolysate was neutralized with $6 \mathrm{~N} \mathrm{NaOH}$. Samples were treated with chloramine $\mathrm{T}$ solution and perchloric acid/aldehyde, as described by Stegemann and Stalder [24]. After incubation for $15 \mathrm{~min}$ at $60^{\circ} \mathrm{C}$, the material was cooled and absorbance was measured at $550 \mathrm{~nm}$ in a spectrophotometer, Ultrospec 2100 (Pro Amersham Biosciences, England). The amount of hydroxyproline in the sample was calculated by comparison with a standard curve of hydroxyproline, and expressed as $\mathrm{mg} / \mathrm{g}$ of wet tissue.

\section{Gelatin zymography}

Tendon fragments $(n=4 /$ group) were incubated in 0.3 $\mathrm{mL}$ of extraction buffer (10 mM cacodylic acid, $\mathrm{pH} 5.0$, $0.15 \mathrm{M} \mathrm{NaCl}, 1 \mu \mathrm{M} \mathrm{ZnCl}$, $20 \mathrm{mM} \mathrm{CaCl}_{2}, 1.5 \mathrm{mM}$ $\mathrm{NaN}_{3}, 0.01 \%$ Triton $\left.\mathrm{X}-100[\mathrm{v} / \mathrm{v}]\right)$, at $4{ }^{\circ} \mathrm{C}$ for 24 hours. After this period, the solution was submitted to centrifugation for 10 minutes $\left(20,000 \times \mathrm{g}\right.$ at $\left.4^{\circ} \mathrm{C}\right)$. Samples were dried and resuspended in the same extraction buffer ( $\mathrm{pH}$ 5.0). Zymography assays were performed on $10 \%$ polyacrylamide electrophoresis gels containing $0.1 \%$ gelatin, using $8 \mu \mathrm{g}$ and $50 \mu \mathrm{g}$ of protein per sample to indentify MMP-2 and MMP-9, respectively. After electrophoresis, the gels were washed with $2.5 \%$ Triton $\mathrm{X}$ 100 at room temperature and incubated overnight in a solution of $50 \mathrm{mM}$ Tris- $\mathrm{HCl}, \mathrm{pH} 8.0,5 \mathrm{mM} \mathrm{CaCl}_{2}$ and $0.02 \% \mathrm{NaN}_{3}$ at $37^{\circ} \mathrm{C}$ for 20 hours. Finally, the gels were stained with Coomassie Brilliant Blue. The protein bands corresponding to gelatinolytic activity were observed after washing the gels with a solution containing $30 \%$ methanol and $10 \%$ acetic acid. The gel was evaluated by band densitometry using the Scion Image program. Each sample was analyzed individually and the experiments were repeated four times, with three gels used for MMP activity quantification while the fourth was incubated in EDTA $(20 \mathrm{mM})$ to confirm the presence of MMPs. The total MMP-2 activity corresponds to the sum of each isoform's activity.

\section{Biomechanical test}

After euthanasia, the right paw with the gastrocnemius and soleus muscles and Achilles tendon was excised. Five tendons of each group were used for the 
mechanical test. They were kept in physiological solution until tested, to prevent drying of the tissues. For the test, the specimens were clamped in a mechanical support with the myotendinous junction and the phalanges at opposite extremities, as employed by Nakagaki and colleagues [25]. The clamp-to-clamp distance was maintained at $7 \mathrm{~mm}$ for all tests. Each tendon was submitted to a pre-conditioning test, with 10 cycles of loading-unloading from 0 to $0.5 \mathrm{~mm}$, at a speed of $20 \mathrm{~mm} /$ min [26] and then submitted to the uniaxial tensile test. During the test, the tendon was subjected to a gradual increase in load at a constant displacement rate of 20 $\mathrm{mm} / \mathrm{min}$ using a load cell of $1 \mathrm{kN}$, until the tendon broke [26]. The data were digitized, displayed and stored in a computer. These data were used to calculate the structural properties (maximum load and displacement at maximum load) and the material properties (maximum stress, strain at maximum stress and modulus of elasticity or Young's modulus) of the tendons in each group [27]. The maximum stress was obtained from the relation between load $(\mathrm{N})$ and cross-section area (CSA) $\left(\mathrm{mm}^{2}\right)$ and expressed in $\mathrm{MPa}$ (megapascal). The CSA was determined according to Goodship and Birch [28]. Each tendon had its shape cast using an alginate dental impression paste (Avagel) manufactured by Dentsply. The CSA mould obtained was cut transversally and photographed. These images were then analyzed with the software Image Pro-Plus. The strain was calculated using the formula $\varepsilon=\Delta \mathrm{L} / \mathrm{L}_{0}$, where $\Delta \mathrm{L}=\mathrm{L}$ $\mathrm{L}_{0}\left(\mathrm{~L}=\right.$ final length and $\mathrm{L}_{0}=$ initial length). Strain was calculated based on clamp-to-clamp displacement. The elastic modulus of each group was measured in the interval corresponding to the most linear region of the stress-strain curve for each sample. The extrinsic stiffness was calculated as the slope of the linear region of the load-displacement curve (in $\mathrm{N} / \mathrm{mm}$ ). The experiments used a machine specifically designed for testing the mechanical properties of materials (MTS, model TETSTAR II) designed by the Laboratory of Mechanical Properties, School of Mechanical Engineering, UNICAMP.

\section{Statistical analysis}

Statistica software (v 8.0) (Tulsa, OK, USA) was used for the statistical analysis. All data were presented as mean \pm standard deviations (S.D.), and a value of $\mathrm{p}<0.05$ was considered significant. The statistical comparison among the control and treated groups was determined using one-way ANOVA followed by the post hoc test of Tukey. In addition, two-way ANOVA was used, when appropriate, to determine how $H$. aphrodisiaca treatment and/or exercise training affected the results, and whether there was interaction between these two conditions.

\section{Results}

\section{Biochemical assay}

Analysis in SDS-PAGE of the Guanidinium chloride extract showed the presence of faint bands of collagen and noncollagenous proteins (NCP) in extracts of animals of the CT group, compared with other groups. This result showed that exercise by itself markedly reduced the presence of collagen and NCP. However H. aphrodisiaca treatment in sedentary rats maintained the same bands as displayed in CS, and also a few additional ones. Furthermore, exercise associated with $H$. aphrodisiaca (HT group) accentuated the appearance of NCP (Figure 1).

The NCP levels, measured by protein analysis with the Bradford method, were significantly decreased $(\mathrm{p}<0.05)$ in animals of the control trained group (CT) when compared to other groups (Figure 2a), confirming the SDSPAGE analysis. Two-way ANOVA showed interaction between training and the treatment with plant infusion for tendon protein content $(\mathrm{p}=0.0008)$. The sulfated glycosaminoglycan levels were statistically similar among all groups (Figure 2b).

Hydroxyproline is an indicator of collagen concentration in tissues. Its content was the highest in HT group (Figure 2c). Two-way ANOVA showed that there was interaction between endurance training and treatment with $H$. aphrodisiaca for hydroxyproline levels in the tendon $(\mathrm{p}=0.005)$.

\section{Zymography analysis}

The zymography (Figure $3 \mathrm{a}$ and $3 \mathrm{~b}$ ) data demonstrated a tendency towards reduction of the activity of MMP-2 isoforms for the CT and HT groups (Figure 3c), but the difference between them was not statistically significant. The total MMP-2 activity was much reduced in the HT group (Figure 3e), when compared with other groups. MMP-9 activity was not statistically different for any of the experimental groups (Figure $3 \mathrm{~d}$ ).

\section{Morphology}

In order to detect proteoglycans within the compression region of the tendon, sections of different experimental groups were stained with Toluidine Blue (Figure 4). Metachromasy was observed in the territorial matrix of the compression region of all groups as a violet coloring, which indicates higher concentrations of negative charges. The trained tendons (Figure $4 \mathrm{c}$ and $4 \mathrm{~d}$ ) had a larger and more intensely stained area compared to sedentary rats (CS and HS) (Figure $4 \mathrm{a}$ and $4 \mathrm{~b}$ ). This staining pattern suggests an increase in the proteoglycan concentration in this region.

The analysis of trained tendons with polarized light microscopy showed intense birefringence in both compression (Figure 5e and 5g) and tension regions (Figure $5 \mathrm{f}$ and $5 \mathrm{~h}$ ), indicating highly organized collagen bundles. 

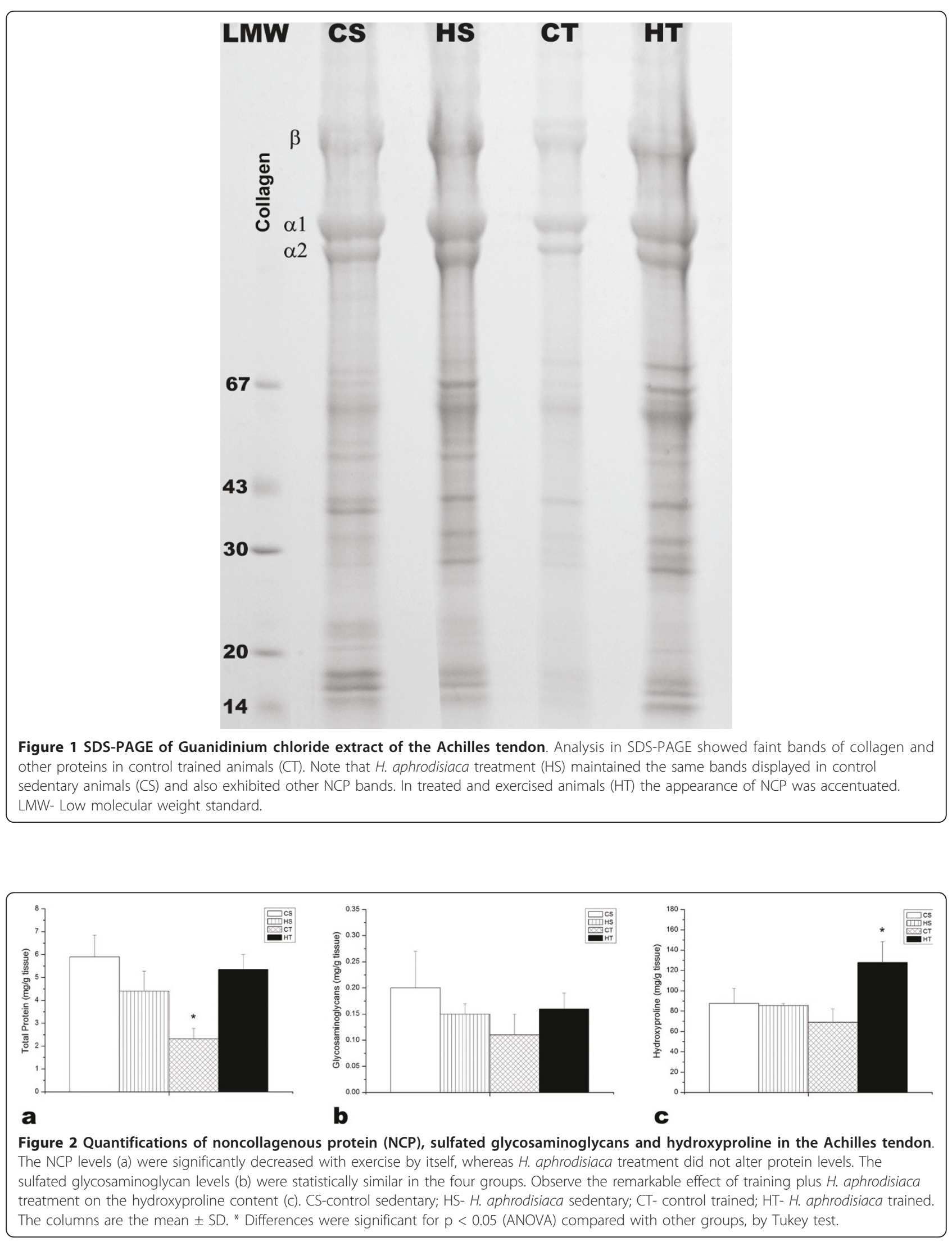


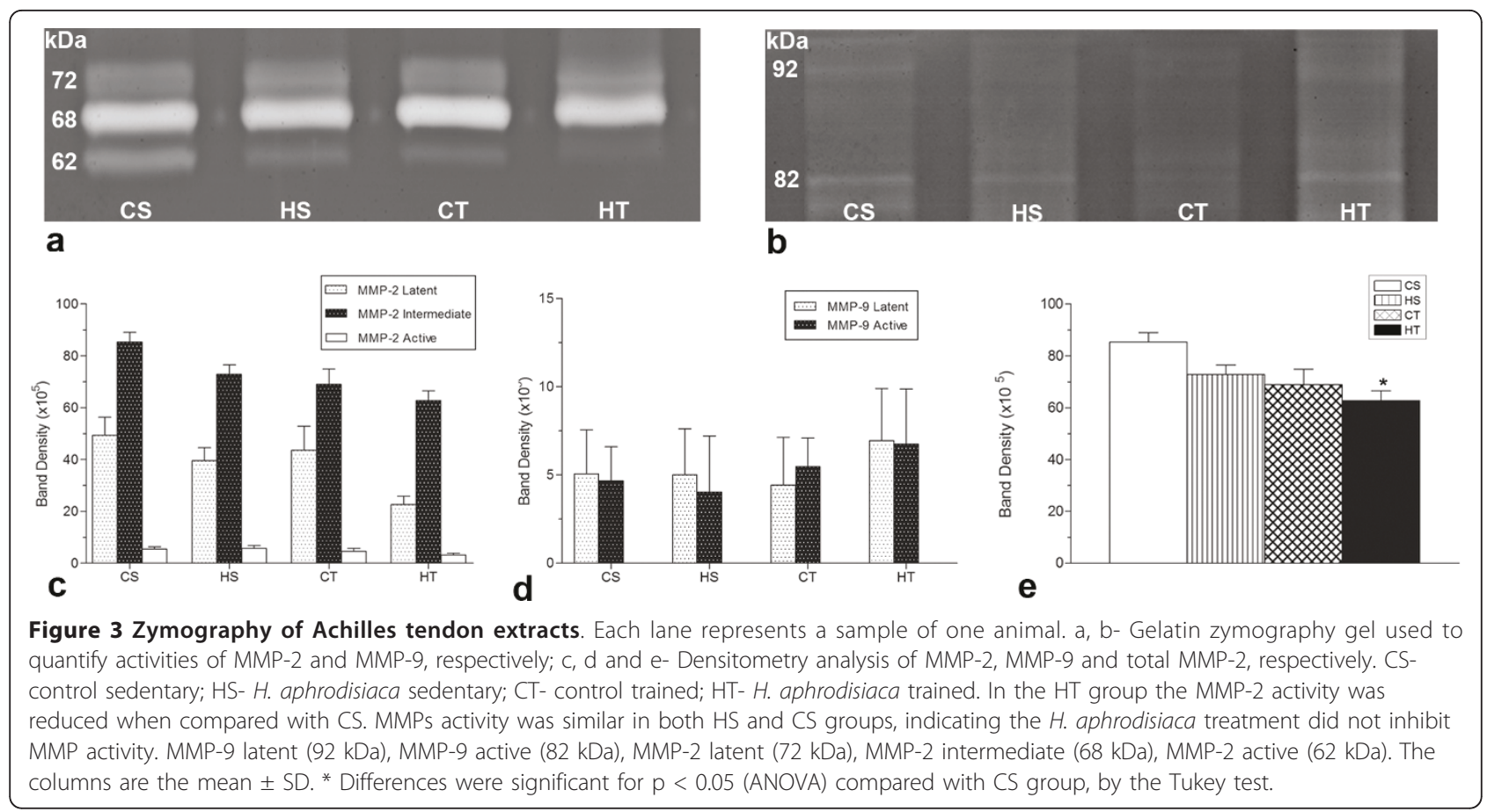

However, the HT group showed the most intense birefringence in both compression and tension regions of the tendon (Figure $5 \mathrm{~g}$ and $5 \mathrm{~h}$ ). Both sedentary groups (Figure 5a, 5b, 5c and 5d) had the same morphological pattern and their collagen bundles were not as well aligned as observed in the trained ones.

\section{Biomechanical Parameters}

The cross-sectional area increased $27 \%$ in HT tendons when compared with CS tendons (means: 3174.00 $\mathrm{mm}^{2} \pm 425.50$ and $2493.2 \mathrm{~mm}^{2} \pm 373.14$, respectively). The other groups did not show alterations in the tendon cross-sectional area. Biomechanical analysis

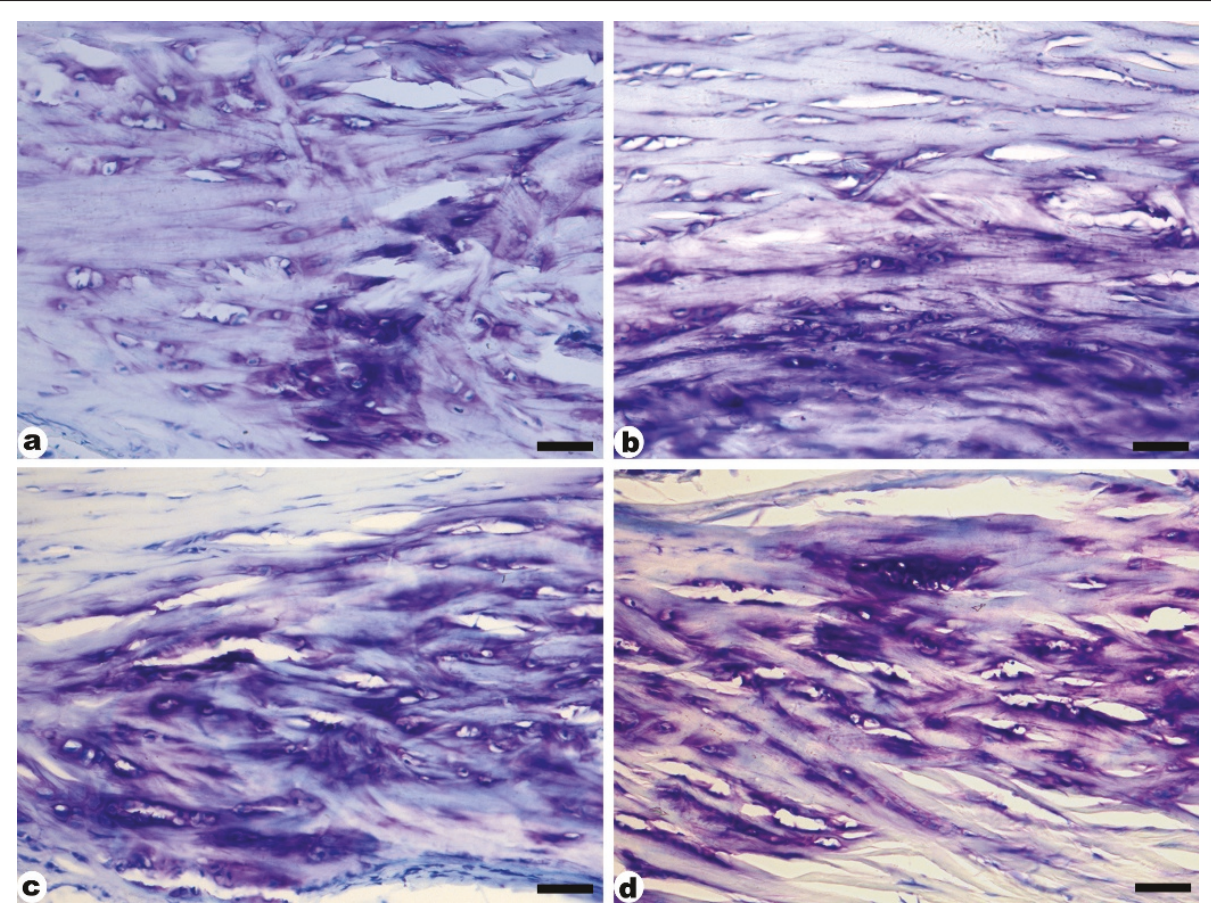

Figure 4 Longitudinal sections of tendons stained with Toluidine Blue. a- control sedentary; b- H. aphrodisiaca sedentary; c-control trained; $\mathrm{d}-\mathrm{H}$. aphrodisiaca trained. Observe intense metachromasy in trained groups $(c, d)$. The treatment with $\mathrm{H}$. aphrodisiaca accentuated metachromasy in sedentary (b) as well as trained (d) rats, compared with their respective controls. Scale bar $=25 \mu \mathrm{m}$. 

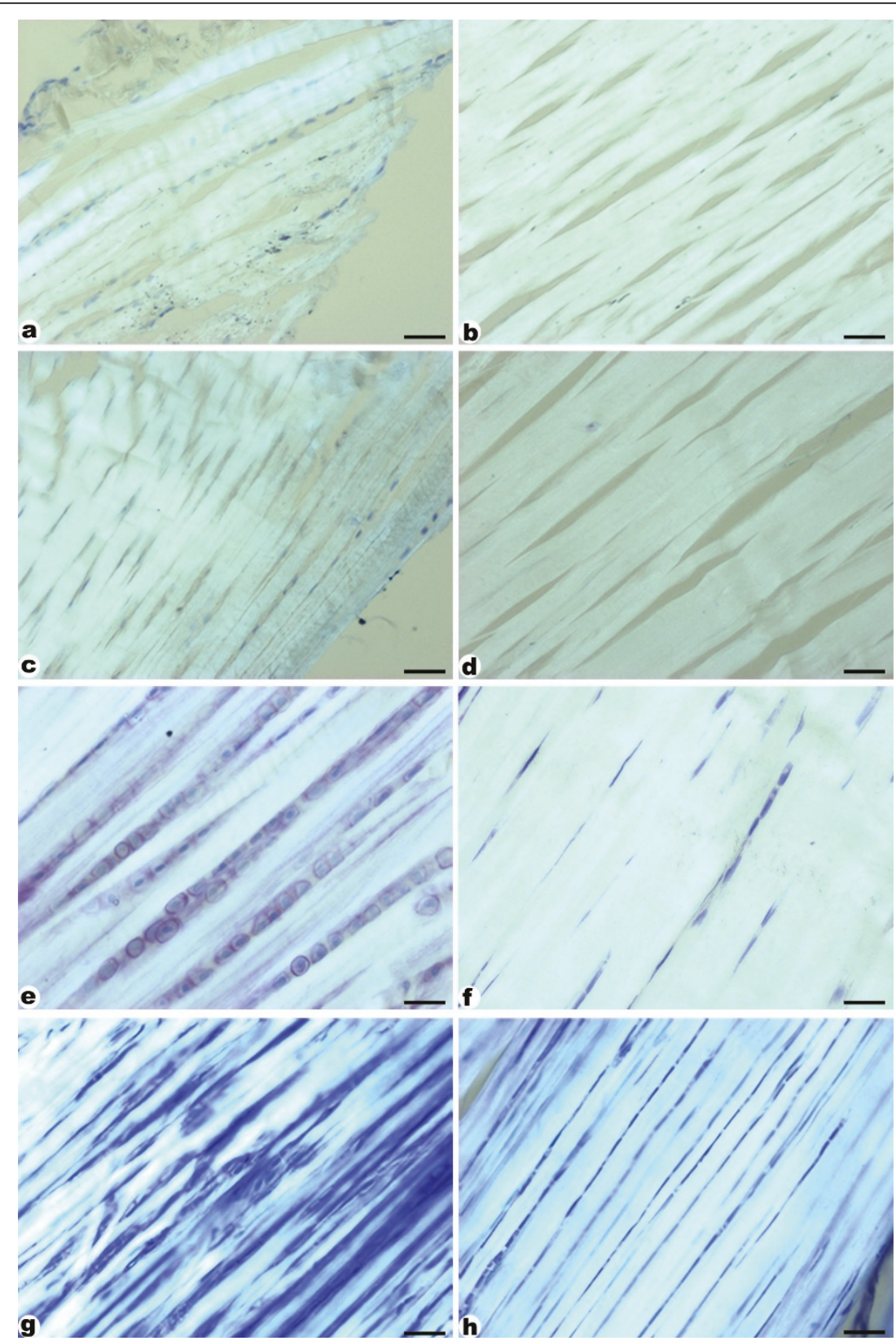

Figure 5 Polarized light microscopy of Toluidine Blue-stained sections. a, b-correspond to control sedentary; C, d- H. aphrodisiaca sedentary; e, f-control trained; and g, h- H. aphrodisiaca trained. The left column corresponds to the compression region and right column corresponds to the tension region. Observe a higher organization of the collagen bundles in tendons of trained (e-h) versus sedentary (a-d) animals. However, the most intense birefringence was found in tendons of trained rats and also those treated with the plant infusion ( $\mathrm{g}$, $\mathrm{h}$ ). The stronger birefringence is due to the increased aggregation and longitudinal organization of the collagen bundles. Scale bar $=30 \mu \mathrm{m}$.

showed significant increase in maximum load (Figure 6a), stiffness (Figure 6c), maximum stress (Figure 6d) and modulus of elasticity (Figure $6 \mathrm{f}$ ) of the tendons of animals trained and treated with $H$. aphrodisiaca (HT). Two-way ANOVA analysis showed that there was interaction between training and treatment with plant infusion only for the maximum stress $(\mathrm{p}=0.006)$. The displacement (Figure 6b) and strain (Figure 6e) were similar in all groups, with no significant difference among them.

\section{Discussion}

The current study shows the biochemical, biomechanical and morphological alterations in Achilles tendon of rats concurrently submitted to endurance training and $H$. aphrodisiaca treatment. 


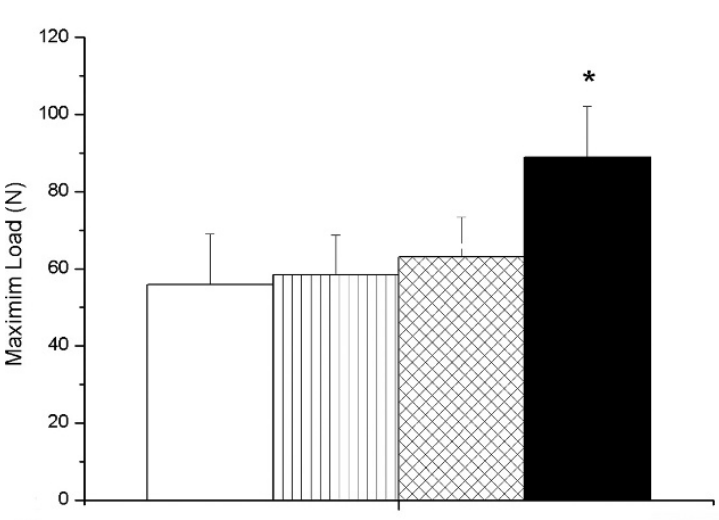

a
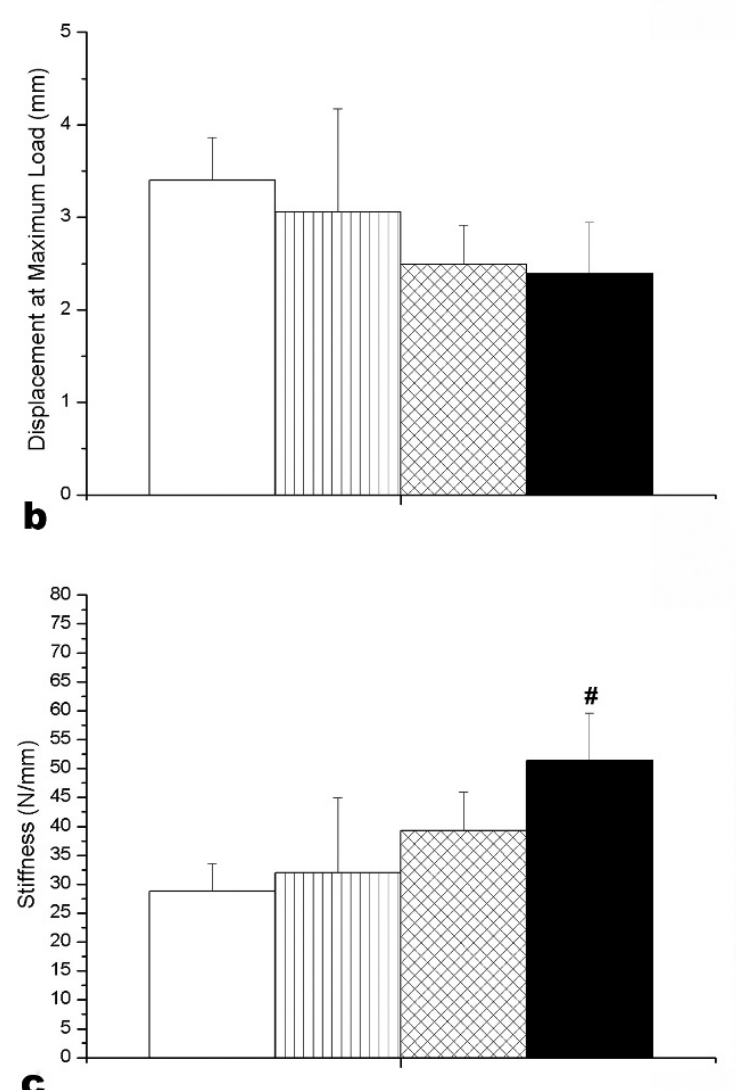

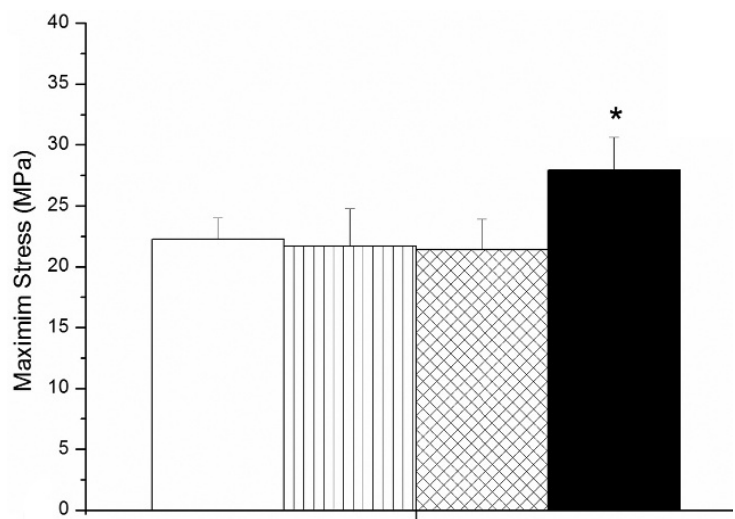

d
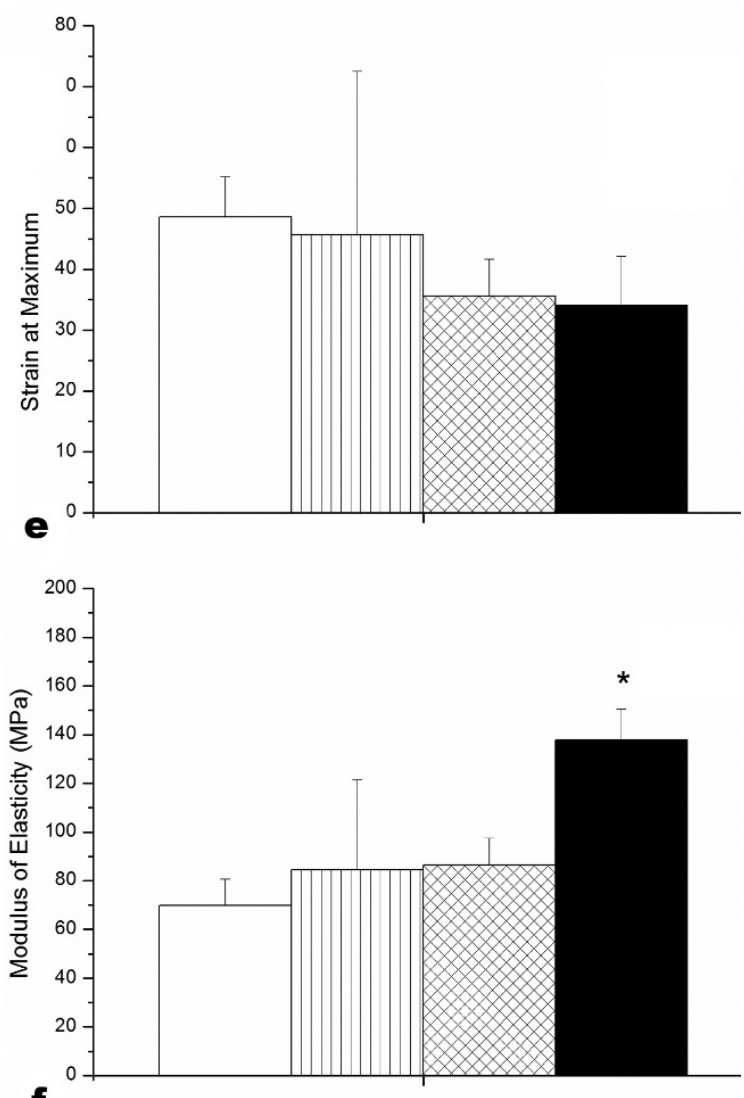

Figure 6 Biomechanical properties of Achilles tendons from control and $H$. aphrodisiaca sedentary and trained rats. The maximum load (a), stiffness (c), maximum stress (d) and modulus of elasticity ( $f$ ), but not displacement (b) and strain (e), were higher in H. aphrodisiaca trained rats. CS- control sedentary; HS- H. aphrodisiaca sedentary; CT- control trained; HT- H. aphrodisiaca trained. The columns are the mean \pm SD. * Differences were significant for $p<0.05$ (ANOVA) compared with other groups, by the Tukey test. \# Differences were significant for $p<0.05$ (ANOVA) compared with CS and HS, by the Tukey test.

The implications of endurance training [29-32] and AAS treatment $[10,13,14]$ on tendon properties have been studied by several investigators. The use of AAS has resulted in a stiffer tendon that failed when submitted to less elongation than was achieved by the control Wistar rats. Exercise did not significantly alter tendon elongation in athlete animals. However, the combination of exercise and steroids significantly increased stiffness and decreased elongation, as well as the energy that the tendon could absorb at tendon failure [13]. In all cases the maximum load that the tendon could withstand did not seem to be affected. However, the use of steroids in the presence of exercise increased the cross-sectional area and reduced the flexibility of the 
tendon [13]. Wood et al. [10] in similar study, reported alterations in collagen content and the toe-limit strain in rats that had been treated with anabolic steroids and exercise.

In the present study, the maximum stress, modulus of elasticity and stiffness were higher in tendons of trained and treated rats, which also exhibited higher hydroxyproline content and increased cross-sectional area. These data showed that HT animals have more resistant tendons, differing from other studies in which the combination of AAS and exercise did not improve the tendon's biomechanical properties [10,13]. Moreover, the interaction between strenuous exercise and $H$. aphrodisiaca promoted significant increase in the material properties (maximum stress and modulus of elasticity) and of collagen content, resulting in stronger tendons able to support intense muscular contraction. Tendons may show a faster response to the number of loading cycles, rather than to the magnitude of the load [16]. Simonsen et al. [33] found that a strength-training regimen (high force with few loading cycles) did not stimulate increase in strength of the Achilles tendon of rats; however, lowforce endurance training (e.g. swimming) resulted in stronger tendons. They suggested that the tendons may respond better to the number of muscle contractions that occur during training rather than the absolute tension exerted by the muscle. In this case, the increased tendon mechanical resistance observed during endurance training and $H$. aphrodisiaca treatment may represent a mechanism to prevent tendon damage due to mechanical fatigue. This biomechanical behavior could be due to the increase of the collagen content, to the fiber orientation and to the interaction between collagen and ground substance [34]. There is a relationship between mechanical properties and collagen content [16], since more resistant tissues have either more collagen per area or collagen fibers with larger diameters [34].

The biomechanical results corroborate the results obtained by polarized microscopy. The organizational aspect of the fibers is better understood when slides are analyzed under polarized microscopy, due to the birefringence properties of collagen bundles. This observation is important because it shows micro-morphological details hidden within these bundles. In the present study, this technique revealed high birefringent brightness due to the condensation and highly tidy fiber array in the trained group. Besides, in the trained group that also received the plant infusion (HT) the results were even more prominent, showing brighter collagen fibers, possibly indicating highly compacted bundles. The lower birefringence found in sedentary animals reflects less organized collagen bundles in these groups.
Some observations in the compression region showed that, in HT animals, there was an increase in the round cell population (stereological data not shown), as well as in the metachromasy intensity, which indicates a greater proteoglycan accumulation due to the increased compressive forces during endurance exercise. However, this result was not confirmed by the GAG dosage, which used the whole tendon. It is important to say that microscopical analysis of sections stained with toluidine blue specifically evaluate a region of the tendon where there is greater accumulation of proteoglycans due to the presence of localized compressive forces, as has been observed in tendons of rats [35] and pigs [36]. Nevertheless, proteoglycans, mainly the low weight ones, are distributed all over the tendon, associated to the collagen fibers [37], probably regulating collagen fibrillogenesis [38].

The degradation of collagen, as well as of a great number of other extracellular matrix compounds, is initiated by metalloproteinases (MMPs). An increase in net MMP activity is likely to indicate matrix degradation and accelerated remodeling $[39,40]$. Increased MMPs activity was verified in human tendons after acute running exercise [39] and in exercised rats (jumping in water) [14]. In the present study, zymography showed that MMP-2 activity in CT animals was similar in the sedentary groups, differing from other studies in which exercise increased the MMPs levels in tendons [14,39]. It is noteworthy that the MMP activity in the above studies was analyzed after only 3 days and 6 weeks of training, respectively.

In the present study, the animals were killed after 11 weeks of training, which means that the MMP activity was evaluated after a long training period. The biomechanical and morphological data demonstrated that the tendons of treated and trained animals had undergone adaptation to the increased demand. Thus, we suggest that there was a period of increased MMP activity to permit tissue remodeling, followed by a period of reduced activity when the tendons were already adapted to the load required. In this case, the mechanical load did not represent a stimulus for the synthesis of proMMPs and their eventual activation. Also, the MMP-9 activity did not alter in the exercised animals, which confirms the tendons' adaptation, since high activity of this protein is associated to the presence of immune cells during the initial inflammatory process [41], which occurs in response to tissue damage caused by exercise. In human tendons, protein synthesis and degradation were chronically elevated 4 weeks after the beginning of the training period, whereas protein synthesis remained high throughout a 12 -week training cycle, while the degradation was slowly reduced. This suggests that there was probably an early period in the exercise program 
when collagen turnover in tendons was increased in order to restructure and readapt the tendon to the increased loading pattern [21].

Marqueti et al. [14] showed that the MMPs activity strongly decreased in AAS-treated animals. The inhibition could be due to a decrease in MMP synthesis or inhibition of activation of latent pro-MMPs. Also, that exercise by itself was not enough to compensate the inhibition of MMP activity induced by AAS treatment. In the present investigation the plant infusion without exercise did not inhibit MMP activity. The data obtained suggests that the infusion associated to exercise could have increased the MMPs' activity in the initial training period (1-3 weeks) when the highest mechanical loading occurred, considering that in the HT group the MMP-2 activity was reduced compared to all other groups, and that in this group the tendons were more resistant, according to the biomechanical results, in relation to the CT group. Therefore, we suggest that remodeling was more efficient in the HT group. However, further research is necessary to evaluate the effect of the plant infusion on MMP activity in exercised animals.

The present study faced some limitations regarding to the applied methodology, such as the lack of specific phytochemical data considering the active compounds present in $H$. aphrodisiaca infusion. Infusion preparation was based on previous studies that have been performed by our group using the same plant species $[3,4,42]$, attempting to mimic the infusion traditionally used by folk medicine. Results of administering $H$. aphrodisiaca without exercise are not significantly different from the control, which would suggest a mandatory exercise program for efficacy of the plant extract altering rat tendons.

Common side effects due to long term endurance exercise together with synthetic AAS intake have been described as: collagen dysplasia, greater stiffness, reduction of strain, impaired tissue remodeling and others, none of which were noticed in this study after the training protocol and plant infusion administration. Scarce but important data lead us believe that there are no deleterious side effects related to $H$. aphrodisiaca intake, which was proved by evaluating blood biochemical parameters as well as kidney and liver morphology after long term administration of the plant infusion (data not published). Based on the promising data presented so far, future experiments crossing the variables of infusion dosages and time could be performed in order to potentiate $H$. aphrodisiaca effects along with endurance exercise. Additionally, phytochemical studies using the same infusion concentration are being carried out to reveal which active components could be related to the anabolic effects shown in this study.

\section{Conclusions}

According to the results found in the present study, it can be concluded that endurance training associated with $H$. aphrodisiaca infusion increases the material properties of tendons. Rather, the association resulted in more resistant tendons, due to the increase in collagen molecules and the corresponding organizational increase. Despite the clearly anabolic effects of $H$. aphrodisiaca and associated endurance training, no side effects were observed, such as those found after synthetic AAS use. Therefore, $H$. aphrodisiaca associated with endurance training contributed to more efficient remodeling of the extracellular matrix, resulting in more resistant tendons to support high loads from intense muscle contraction. These findings suggest that $H$. aphrodisiaca infusion is a potential aid to optimize tendon remodeling in athletes, where the disparity of the faster physiological muscle adjustment in relation to the tendon often leads to lesions, because the tendons may not resist the increased tension produced by the stronger muscles.

\section{List of abbreviations}

CS: control sedentary; HS: H. aphrodisiaca sedentary; CT: control trained; HT: H. aphrodisiaca trained; AAS: anabolic androgenic steroids; MMP: matrix metalloproteinase; GuHCl: guanidine chloride; PMSF: phenylmethylsulfonyl fluoride; EDTA: ethylenediamine tetraacetic acid; BSA: bovine serum albumin; GAG: glycosaminoglycans; DMMB: dimethylmethylene blue; CSA: crosssection area; NCP: noncollagenous proteins.

\section{Acknowledgements}

This work was supported by Fundação de Amparo à Pesquisa do Estado de São Paulo (FAPESP) (Grant numbers: 06/06132-2 and 08/05610-3) and by Coordenação de Aperfeiçoamento de Pessoal de Nível Superior (CAPESPROEX). The authors thank Dr. Gerson E. R. Campos for providing the treadmill to train the animals, Andrea Aro for helping in the discussion and Rodrigo Leite for English reviewing.

\section{Author details}

'Departamento de Ciências Agrárias e Biológicas, Centro Universitário Norte do Espírito Santo, Universidade Federal do Espírito Santo, BR 101 Norte - Km 60, CEP 29932-540, São Mateus, ES, Brasil. ²Departamento de Biologia Estrutural e Funcional, Instituto de Biologia, Universidade Estadual de Campinas, CEP 13083-863, CP 6109, Campinas, SP, Brasil. ²Departamento de Histologia, Instituto de Ciências Biomédicas, Universidade Federal de Uberlândia, CEP 38400-902, CP 592, Uberlândia, MG, Brasil. Departamento de Bioquímica, Instituto de Biologia, Universidade Estadual de Campinas, CEP 13083-863, CP 6109, Campinas, SP, Brasil.

\section{Authors' contributions}

JCM participated in all aspects of the work. The co-authors participated in the discussion of the results and revision of the manuscript, as well as in the following contributions: MLMG and MMS participated in the training program and the processing of the material; TCT participated in the morphological and biochemical analyses; WRN participated in the biomechanical analysis; DLF participated in the zymographical analysis; ERP and HD participated in supervision and as sponsors. All authors read and approved the final manuscript.

\section{Competing interests}

The authors declare that they have no competing interests.

Received: 21 February 2011 Accepted: 28 June 2011 Published: 28 June 2011 


\section{References}

1. Pio Corrêa M: Dicionário de Plantas Úteis do Brasil e das Exóticas Cultivadas. Rio de Janeiro. 1984

2. Pott A, Pott VJ: Plantas do Pantanal. Empresa Brasileira de Pesquisa agropecuária do Pantanal, Corumbà. 1994.

3. Chieregato LC: Efeito do tratamento crônico com extratos de Heteropterys aphrodisiaca O.Mach e Anemopaegma arvense (Vell.) Stellf no testículo de ratos Wistar adultos. Viçosa: UFV; 2005.

4. Monteiro JC, Predes FS, Matta SL, Dolder H: Heteropterys aphrodisiaca infusion reduces the collateral effects of cyclosporine $A$ on the testis. Anat Rec (Hoboken) 2008, 291(7):809-817.

5. Kam PC, Yarrow M: Anabolic steroid abuse: physiological and anaesthetic considerations. Anaesthesia 2005, 60(7):685-692.

6. Creasy DM: Pathogenesis of male reproductive toxicity. Toxicologic pathology 2001, 29(1):64-76

7. Bahrke MS, Yesalis CE: Abuse of anabolic androgenic steroids and related substances in sport and exercise. Current opinion in pharmacology 2004, 4(6):614-620.

8. Bach BR Jr, Warren RF, Wickiewicz TL: Triceps rupture. A case report and literature review. The American journal of sports medicine 1987, 15(3):285-289.

9. Battista V, Combs J, Warme WJ: Asynchronous bilateral Achilles tendon ruptures and androstenediol use. The American journal of sports medicine 2003, 31(6):1007-1009.

10. Wood TO, Cooke PH, Goodship AE: The effect of exercise and anabolic steroids on the mechanical properties and crimp morphology of the rat tendon. American Orthopaedic Society for Sports Medicine; 1988:16:153.

11. Michna $\mathrm{H}$ : Tendon injuries induced by exercise and anabolic steroids in experimental mice. International orthopaedics 1987, 11(2):157-162.

12. Inhofe PD, Grana WA, Egle D, Min KW, Tomasek J: The effects of anabolic steroids on rat tendon. An ultrastructural, biomechanical, and biochemical analysis. The American journal of sports medicine 1995, 23(2):227-232

13. Miles JW, Grana WA, Egle D, Min KW, Chitwood J: The effect of anabolic steroids on the biomechanical and histological properties of rat tendon. The Journal of bone and joint surgery 1992, 74(3):411-422.

14. Marqueti RC, Parizotto NA, Chriguer RS, Perez SE, Selistre-de-Araujo HS Androgenic-anabolic steroids associated with mechanical loading inhibit matrix metallopeptidase activity and affect the remodeling of the Achilles tendon in rats. The American journal of sports medicine 2006, 34(8):1274-1280

15. Marz J, Novotny P: Pectoralis maior tendon rupture and anabolic steroids in anamnesis-a case review. Rozhl Chir 2008, 87(7):380-383.

16. Buchanan Cl, Marsh RL: Effects of exercise on the biomechanical, biochemical and structural properties of tendons. Comparative biochemistry and physiology 2002, 133(4):1101-1107.

17. Demirel HA, Powers SK, Zergeroglu MA, Shanely RA, Hamilton K, Coombes J, Naito $\mathrm{H}$ : Short-term exercise improves myocardial tolerance to in vivo ischemia-reperfusion in the rat. $\int$ Appl Physiol 2001 91(5):2205-2212

18. Fontana K, Oliveira HC, Leonardo MB, Mandarim-de-Lacerda CA, da CruzHofling MA: Adverse effect of the anabolic-androgenic steroid mesterolone on cardiac remodelling and lipoprotein profile is attenuated by aerobic exercise training. International journal of experimental pathology 2008, 89(5):358-366.

19. Moraska A, Deak T, Spencer RL, Roth D, Fleshner M: Treadmill running produces both positive and negative physiological adaptations in Sprague-Dawley rats. Am Physiological Soc; 2000:279:1321

20. Smolka MB, Zoppi CC, Alves AA, Silveira LR, Marangoni S, Pereira-Da-Silva L, Novello JC, Macedo DV: HSP72 as a complementary protection against oxidative stress induced by exercise in the soleus muscle of rats. Am Physiological Soc; 2000:279:R1539.

21. Zingales B: Analysis of protein by sodium dodecyl sulphateprolyacrylamide gel electrophoresis. J Biol Chem 1984, 44:4406-4412.

22. Bradford MM: A rapid and sensitive method for the quantitation of microgram quantities of protein utilizing the principle of protein-dye binding. Analytical biochemistry 1976, 72:248-254

23. Farndale RW, Buttle DJ, Barrett AJ: Improved quantitation and discrimination of sulphated glycosaminoglycans by use of dimethylmethylene blue. Elsevier; 1986:883:173-177.
24. Stegemann H, Stalder K: Determination of hydroxyproline. Clinica chimica acta; international journal of clinical chemistry 1967, 18(2):267-273.

25. Nakagaki WR, Biancalana A, Benevides GP, Gomes L: Biomechanical and biochemical properties of chicken calcaneal tendon under effect of age and nonforced active exercise. Connective tissue research 2007 48(5):219-228

26. Tohyama $H$, Yasuda $K$ : The effects of stress enhancement on the extracellular matrix and fibroblasts in the patellar tendon. Journal of biomechanics 2000, 33(5):559-565.

27. Gupte CM, Smith A, Jamieson N, Bull AM, Thomas RD, Amis AA: Meniscofemoral ligaments-structural and material properties. Journal of biomechanics 2002, 35(12):1623-1629.

28. Goodship AE, Birch HL: Cross sectional area measurement of tendon and ligament in vitro: a simple, rapid, non-destructive technique. Journal of biomechanics 2005, 38(3):605-608

29. Huang TF, Perry SM, Soslowsky LJ: The effect of overuse activity on Achilles tendon in an animal model: a biomechanical study. Annals of biomedical engineering 2004, 32(3):336-341.

30. Viidik A: Tensile strength properties of Achilles tendon systems in trained and untrained rabbits. Acta orthopaedica Scandinavica 1969, 40(2):261-272

31. Vilarta R, Vidal Bde C: Anisotropic and biomechanical properties of tendons modified by exercise and denervation: aggregation and macromolecular order in collagen bundles. Matrix (Stuttgart, Germany) 1989, 9(1):55-61.

32. Woo SL, Ritter MA, Amiel D, Sanders TM, Gomez MA, Kuei SC, Garfin SR, Akeson WH: The biomechanical and biochemical properties of swine tendons-long term effects of exercise on the digital extensors. Connective tissue research 1980, 7(3):177-183.

33. Simonsen EB, Klitgaard H, Bojsen-Moller F: The influence of strength training, swim training and ageing on the Achilles tendon and $\mathrm{m}$. soleus of the rat. Journal of sports sciences 1995, 13(4):291-295.

34. Woo SL, Debski RE, Withrow JD, Janaushek MA: Biomechanics of knee ligaments. The American journal of sports medicine 1999, 27(4):533-543.

35. Covizi DZ, Felisbino SL, Gomes L, Pimentel ER, Carvalho HF: Regional adaptations in three rat tendons. Tissue \& cell 2001, 33(5):483-490.

36. Feitosa V, Vidal BC, Pimentel ER: Optical anisotropy of a pig tendon under compression. Journal of anatomy 2002, 200(Pt 1):105-111.

37. Cribb AM, Scott JE: Tendon response to tensile stress: an ultrastructural investigation of collagen: proteoglycan interactions in stressed tendon Journal of anatomy 1995, 187(Pt 2):423-428

38. Vogel KG, Meyers $A B$ : Proteins in the tensile region of adult bovine deep flexor tendon. Clinical orthopaedics and related research 1999, , 367 Suppl: S344-355.

39. Koskinen SOA, Heinemeier KM, Olesen $J L$, Langberg H, Kjaer M: Physica exercise can influence local levels of matrix metalloproteinases and their inhibitors in tendon-related connective tissue. Am Physiological Soci 2004:96:861

40. Riley GP: Gene expression and matrix turnover in overused and damaged tendons. Scandinavian journal of medicine \& science in sports 2005, 15(4):241-251.

41. Clutterbuck AL, Harris P, Allaway D, Mobasheri A: Matrix metalloproteinases in inflammatory pathologies of the horse. Vet J 2008, 183(1):27-38.

42. Gomes MLM: Efeitos da infusão de nó-de-cachorro (Hetereopterys aphrodisiaca, O. Mach.) sobre a morfologia e estrutura testicular de ratos Wistar adultos, submetidos a treinamento físico. Campinas: UNICAMP; 2011

\section{Pre-publication history}

The pre-publication history for this paper can be accessed here: http://www.biomedcentral.com/1472-6882/11/51/prepub

doi:10.1186/1472-6882-11-51

Cite this article as: Monteiro et al:: More resistant tendons obtained from the association of Heteropterys aphrodisiaca and endurance training. BMC Complementary and Alternative Medicine 2011 11:51. 